\title{
Biodiversity of Root-Nodule Bacteria Associated With the Leguminous Plant Biserrula pelecinus
}

\author{
ARTICLE in SOIL SCIENCE · JULY 2009 \\ Impact Factor: 0.79 - DOI: 10.1097/SS.0b013e3181b655a2
}

4 AUTHORS, INCLUDING:

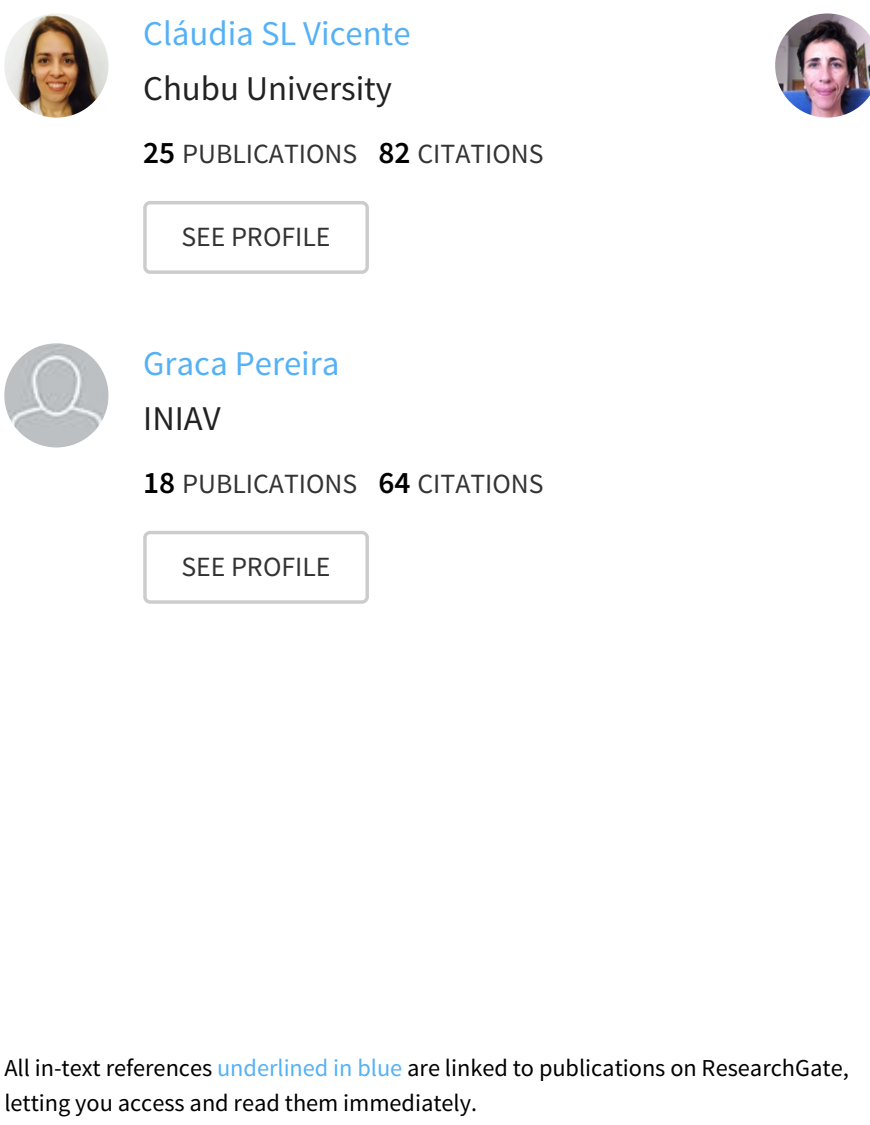

María Pérez-Fernández

Universidad Pablo de Olavide

79 PUBLICATIONS 477 CITATIONS

SEE PROFILE 


\title{
Biodiversity of Root-Nodule Bacteria Associated With the Leguminous Plant Biserrula pelecinus
}

\author{
Cláudia S. L. Vicente, ${ }^{1,2}$ Maria A. Pérez-Fernández, ${ }^{2}$ Graça Pereira, ${ }^{1}$ and Manuel M. Tavares-de-Sousa ${ }^{1}$
}

\begin{abstract}
Biserrula pelecinus is a noteworthy forage legume known for its drought- and acid-resistant properties and nitrogen-fixing ability that forms an extremely specific symbiotic relationship with bacteria from genera Mesorhizobium. To investigate the biodiversity of rootnodule bacteria associated with $B$. pelecinus, a total of 88 bacterial strains were examined using rep-polymerase chain reaction amplification. The 16S rRNA gene sequencing was also used to determine the phylogenetic relationship with type strains of different genera of rhizobia. Our results show that although a considerable genetic variability among Biserrula isolates was found, most isolates were phylogenetically related to Mesorhizobium ciceri. Curiously, a new symbiotic partner was found to nodulate Biserrula, suggesting possible lateral gene transfer of nodulation and nitrogen fixation genes between Mesorhizobium and Rhizobium.
\end{abstract}

Key words: Mesorhizobium, biodiversity, pasture, Biserrula pelecinus (Soil Sci 2009;174: 424-429)

$T^{1}$ he successful establishment of legume plants is strongly affected by inoculation with symbiotic bacteria, which, in turn, should be able to effectively colonize the rhizosphere, being highly competitive with other soil rhizobia and to have genetic compatibility with the legume host. Considering the genetic variation of legume populations, the genetic diversity of rhizobia and its influence on host-rhizobia relationships should also be considered in the development of new legume species (Loi et al., 1999; 1997).

Native to the Mediterranean basin, Biserrula pelecinus is an annual legume adapted to desert-like conditions, surviving in acidic sandy soils, with poor nutrient-content and low precipitation conditions (Loi et al., 1999; 2001). Thus, Biserrula is an ideal plant to be introduced into semiarid Mediterranean pastures as a regenerating legume. The symbiotic bacteria associated with $B$. pelecinus have been, recently, identified as Mesorhizobium ciceri biovar biserrulae. This new species is distinguished from $M$. ciceri by significant differences in growth conditions, antibiotic resistance, carbon source utilization, and as well in similarity between symbiotic genes (Nandasena et al., 2007). In addition, the symbiotic relationship established between Biserrula and mesorhizobia is defined as being extremely specific. Nandasena et al. (2004) found that specific strains originated from $B$. pelecinus had a specific host range and did not nodulate several legumes, such as Amorpha fruticosa L., Astragalus sinicus L., Cicer arietinum L., Hedysarum spinosissimum

${ }^{1}$ Instituto Nacional de Recursos Biológicos, L-INIA-Elvas, Apartado 6, 7350 Elvas, Portugal. Ms. Vicente is corresponding author. E-mail: claudia. s.vicente@gmail.com

${ }^{2}$ Departamento de Sistemas Fisicos, Quimicos y Naturales, Universidad Pablo de Olavide, Carretera de Utrera, Sevilla, Spain.

Received January 30, 2009.

Accepted for publication July 7, 2009.

Copyright (C) 2009 by Lippincott Williams \& Wilkins, Inc.

ISSN: 0038-075X

DOI: $10.1097 / \mathrm{SS} .0 \mathrm{~b} 013 \mathrm{e} 3181 \mathrm{~b} 655 \mathrm{a} 2$
L., Lotus parviflorus Desf., Macroptilium atropurpureum (DC) Urb, and Trifolium lupinaster $\mathrm{L}$.

In parallel to breeding and improvement of Biserrula legume varieties, this study concerns the first approach to the development of a new commercial rhizobia strain specific to Biserrula and efficiently adapted to semiarid Mediterranean regions of Iberian Peninsula. In this work, we analyzed the genetic diversity of root-nodule bacteria isolated from endemic B. pelecinus collected in geographically distinct locations across northern Spain and southern Portugal (Table 1). We intend to select, based on DNA fingerprinting techniques, different rootnodule bacteria for further phenotypic characterization and evaluation of infective and effectiveness potential of rhizobia isolates.

\section{MATERIALS AND METHODS}

\section{Sampling Procedures and Isolation of Bacterial Strains}

Within each field site, undisturbed spots were randomly chosen. Topsoil samples were collected from a depth of 0 to $15 \mathrm{~cm}$, and healthy plants of $B$. pelecinus were screened for fresh and effective nodulation. Individual plant roots with nodules were sealed in plastic bags and transferred to the laboratory. Standard procedures of collection and isolation of rootnodule bacteria were performed as described by Vincent (1970). After surface sterilization, nodules were individually macerated, and the milky suspension was streaked onto yeast mannitol agar plates (Vincent, 1970). Pure cultures were obtained by selection of a single colony with typical morphology of rhizobia (Jordan, 1984).

\section{BOX and ERIC-PCR Fingerprinting}

Genomic DNA of each root-nodule bacteria was extracted as described by alkaline hydrolysis method (Sambrook and Russel, 2001). Molecular fingerprint of all isolates, including a sample of the commercial strain of B. pelecinus, Mesorhizobium species, were carried out with BOX and ERIC primers (De Bruijn, 1992; De Bruijn et al., 1996). The amplification reactions contained $40 \mathrm{ng}$ of DNA, $1 \times$ buffer Taq polymerase (Fermentas), $1 \mathrm{U}$ Taq DNA polymerase (Fermentas), $0.2 \mathrm{mmol} / \mathrm{L}$ from each dNTP, $0.5 \mu \mathrm{mol} / \mathrm{L}$ from each primer, in a final volume of $25 \mu \mathrm{L}$. Amplification was conducted in a Biometra UNO II thermocycler. The polymerase chain reaction (PCR) amplification program consisted of a first cycle at $95{ }^{\circ} \mathrm{C}$ for 5 minutes; 35 cycles of $94{ }^{\circ} \mathrm{C}$ for 30 seconds, $53{ }^{\circ} \mathrm{C}$ (BOX A1R) or $52{ }^{\circ} \mathrm{C}$ (ERIC-R and ERIC-F) for 1 minute, $72{ }^{\circ} \mathrm{C}$ for 1.5 minutes, and a final extension at $72{ }^{\circ} \mathrm{C}$ for 7 minutes. The reproducibility of the PCR amplifications was validated twice. The PCR products were separated by electrophoresis on $1.5 \%$ agarose gel in TBE $0.5 \times$ buffer, stained with ethidium bromide, and photographed using the Electrophoresis Documentation and Analysis System 120 Kodak. The size of the DNA fragments was estimated by comparison with a 100-bp molecular marker (Gene Ruler DNA ladder, MBI, Fermentas) and recorded in a binary form 
TABLE 1. Geographic Data From Collection Sites in Spain and Portugal

\begin{tabular}{lccccc}
\hline & & \multicolumn{3}{c}{ Geographic Coordinates } & \\
\cline { 3 - 5 } Site & Location & Latitude & Longitude & Altitude, m & Soil Type \\
\hline 1 & Ávila (Sp) & $40^{\circ} 27^{\prime} 27^{\prime \prime}$ & $5^{\circ} 19^{\prime} 33^{\prime \prime}$ & 1062 & Cambisol \\
2 & Elvas (Pt) & $39^{\circ} 32^{\prime} 45^{\prime \prime}$ & $7^{\circ} 35^{\prime} 43^{\prime \prime}$ & 268 & Luvisol \\
3 & Monsaraz (Pt) & $38^{\circ} 26^{\prime} 53^{\prime \prime}$ & $7^{\circ} 24^{\prime} 8^{\prime \prime}$ & 191 & Luvisol \\
4 & Ajuda (Pt) & $38^{\circ} 46^{\prime} 43^{\prime \prime}$ & $7^{\circ} 10^{\prime} 16^{\prime \prime}$ & 166 & Cambisol \\
5 & Arronches (Pt) & $39^{\circ} 04^{\prime} 07^{\prime \prime}$ & $7^{\circ} 15^{\prime} 36^{\prime \prime}$ & 277 & Semiarid Mediterranean \\
6 & Terena (Pt) & $38^{\circ} 38^{\prime} 00^{\prime \prime}$ & $7^{\circ} 15^{\prime} 36^{\prime \prime}$ & 277 & Cambisol \\
7 & Safara (Pt) & $38^{\circ} 06^{\prime} 44^{\prime \prime}$ & $7^{\circ} 14^{\prime} 7^{\prime \prime}$ & Luvisol & Luvisol \\
\hline
\end{tabular}

Pt: Portugal; Sp: Spain.

( 0 , absence of band; 1 , presence of band). The binary matrices from BOX and ERIC primers were combined using NTedit from the software NTSYSpc version 2.0b (Rohlf, 1990). DNA fingerprint analysis was inferred by a dendrogram constructed using the unweighted pair group method with arithmetic mean algorithm (UPGMA) (Backeljau et al., 1996) and the Jaccard similarity coefficient (J) (Mantel, 1967). Goodness of fit of the cluster analysis was determined by a cophenetic value matrix (CCC) (Romesburg, 1984).

\section{Partial 16S rRNA Sequence Analysis}

Amplification of 16S rRNA gene was conducted using the universal primers $63 \mathrm{f}$ and $1387 \mathrm{r}$ (Marchesi et al., 1998). The PCR reactions contained 40 ng of DNA, $1 \times$ buffer Taq polymerase, $1 \mathrm{U}$ Taq DNA polymerase (Fermentas), $0.2 \mathrm{mmol} / \mathrm{L}$ from each dNTP, $0.5 \mu \mathrm{mol} / \mathrm{L}$ from each primer, for a volume of $25 \mu \mathrm{L}$. The amplification program was $94{ }^{\circ} \mathrm{C}$ for 1 minute ( 1 cycle); 30 cycles of $94{ }^{\circ} \mathrm{C}$ for 1 minute, $55^{\circ} \mathrm{C}$ for 1 minute, $72{ }^{\circ} \mathrm{C}$ for 1.5 minutes; and $72{ }^{\circ} \mathrm{C}$ for 7 minutes ( 1 cycle). The PCR products were purified by the PureLink Quick Gel Extraction Kit (Invitrogen, Paisley, UK) and sequenced at STABVIDA Lda (Oeiras, Lisbon, Portugal). Partial sequences of 16S rRNA gene obtained using primer $1387 \mathrm{r}$ were submitted to BLASTN search (NCBI) for significant nucleotide sequence alignments and to GenBank for assignment of accession numbers. An unrooted phylogenetic tree was constructed by MEGA4 software (Tamura et al., 2007), using nucleotide sequences of Biserrula bacterial isolates and five species representative of the five main genera of rhizobia (Mesorhizobium, Sinorhizobium, Azorhizobium, Bradyrhizobium, and Rhizobium). The evolutionary distance was computed as described by Jukes and Cantor (1969), and the evolutionary tree was inferred by the neighbor-joining method (Saitou and Nei, 1987). A bootstrap analysis based on 1000 replicates of neighbor-joining data was performed (Felsenstein, 1985).

\section{RESULTS}

\section{Isolation of Root-Nodule Bacteria}

Eighty-eight bacterial isolates exhibited similar phenotypic characteristics of rhizobia culture, expressed by milky translucence with moderate-to-copious extracellular polysaccharides colonies (Jordan, 1984) after a period of incubation ranging between 3 and 8 days.

\section{BOX and ERIC-PCR Fingerprinting}

BOX and ERIC-PCR amplification generated complex DNA patterns for all root-nodule isolates. To assure a correct molecular characterization, a total of 12 polymorphic bands with a size ranging between 630 and $1600 \mathrm{bp}(\mathrm{BOX})$ and 180 and 850 bp (ERIC) were analyzed (Fig. 1). The dendrogram (Fig. 2) revealed considerable genetic diversity among Biserrula rootnodule isolates, with a cophenetic coefficient of 0.81 . Two main groups were described with approximately $72 \%$ similarity to Mesorhizobium species-type strain. Groups A and B contained, respectively, $59 \%$ and $41 \%$ of Biserrula isolates. Six subgroups were also defined in Group A. Isolates ElvPt18 and SafPt1, within subgroup A1, shared the highest similarity percentage with Mesorhizobium species. Subgroups A3 and A4 had a low polymorphism between root-nodules because the great majority shared the same DNA banding pattern. Group B gradually branches with bacterial isolates with clearly distinct patterns, resulting in a decrease of similarity with the type strain. Seven subgroups and two isolates, ArrPt11 and ArrPt12, which share

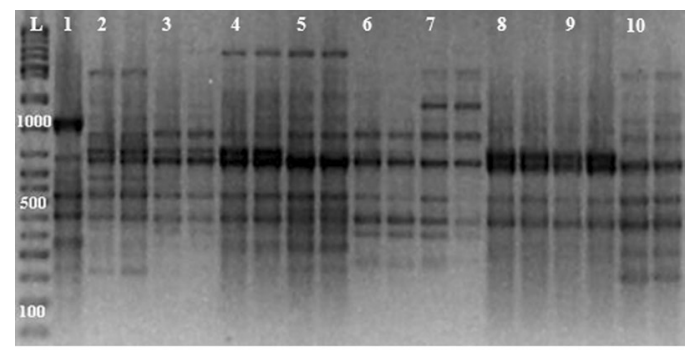

A

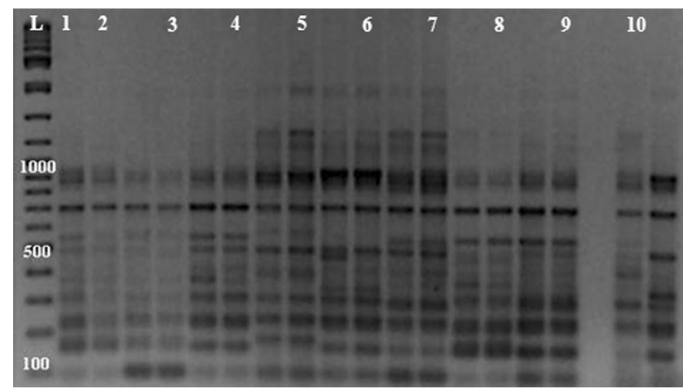

B

FIG. 1. Molecular fingerprints of Biserrula root-nodule bacteria using BOX (A) and ERIC (B) primers. DNA samples of each bacterial isolate were amplified in duplicate. $L$ (DNA ladder $100 \mathrm{bp}$ ). The lanes are labeled by number and not by strain type: $(A): 1$, Mesorhizobium species; 2, MonPt12; 3, MonPt13; 4, MonPt14; 5 , MonPt15; 6, MonPt16; 7, MonPt17; 8, MonPt18; 9, AjuPt1; 10, AjuPt2. (B) 1, AjuP6; 2, AjuPt7; 3, AjuPt8; 4, AjuPt10; 5, AjuPt1 1; 6, AjuPt12; 7, AjuPt13; 8, AjuPt15; 9, AjuPt16; 10, AjuPt17. 


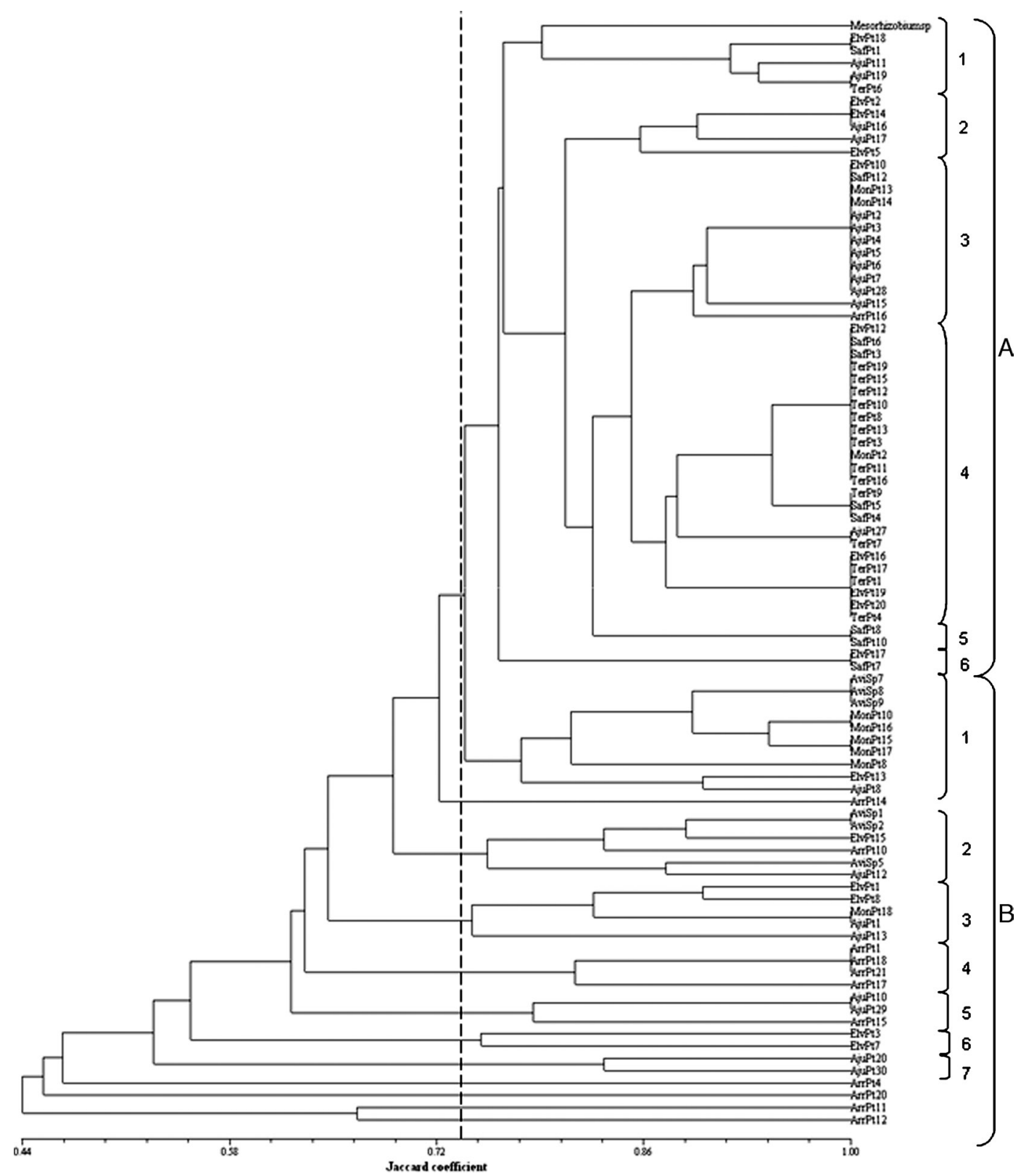

FIG. 2. Dendrogram showing the relatedness of $B$. pelecinus isolates as determined by BOX + ERIC combined fingerprint data analysis. Relationship was determined using Jaccard similarity coefficient and UPGMA clustering method.

only $44 \%$ of similarity with the other bacteria, were described. From the 88 root-nodule bacteria initially characterized, 56 bacteria with different band patterns were selected for phenotypic and effectiveness tests.

\section{Partial 16S rRNA Sequence Analysis}

A partial fragment of $16 \mathrm{~S}$ rRNA gene, approximately 1000 bp, was amplified and sequenced for five representative bacterial isolates belonging to the main groups of the dendrogram (Group A, AjuPt16, SafPt12, and SafPt6; Group B, AviSp7 and ArrPt12). Nucleotide sequences were first submitted to NCBI BLASTN to search for close relations through sequence similarity. The isolate AjuPt16, with a sequence length of 1008 bp, shared 94\% of maximum identity with bacterial strains belonging to the genera $M$. ciceri and M. ciceri bv. biserrulae strain WSM1271 (AY601513). Identical results were also obtained for strains SafPt12, SafPt6, and AviSp7. For isolate ArrPt12, a BLASTN search retrieved $97 \%$ maximum identity with Rhizobium leguminosarum bv. phaseoli. An unrooted phylogenetic tree was developed using the model by Jukes and Cantor (1969) and the neighbor-joining method (Saitou and Nei, 1987) (Fig. 3). The reliability of the evolutionary tree was assessed by the bootstrap test (confidence values estimated from 1000 replication of each sequence) (Felsenstein, 1985). The phylogenetic tree was divided in two groups: Group 1, where Biserrula bacteria AjuPt6, SafPt6, SafPt12, and AviSp7 were grouped with M. ciceri bv. biserrulae (AY601513), M. ciceri (U07934), and M. loti (X67229); and Group 2, which presented ArrPt12, clearly 


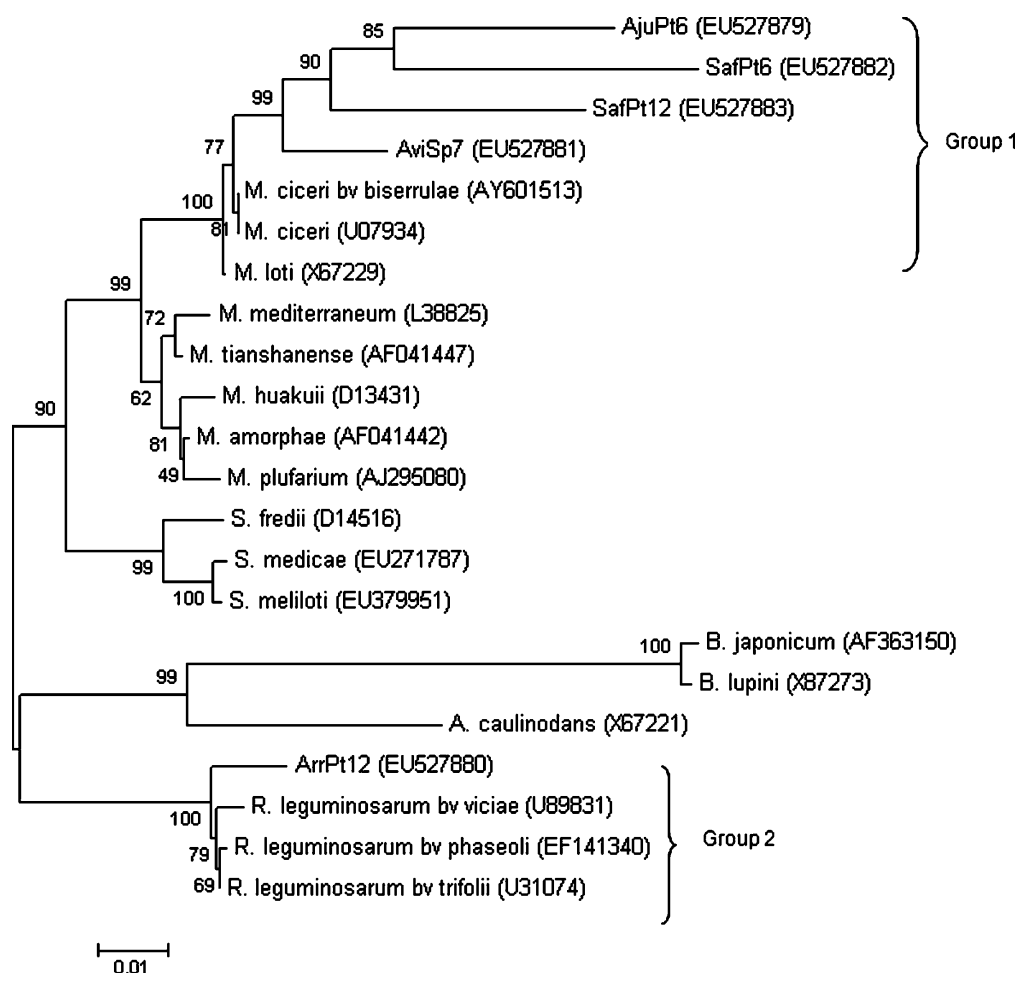

FIG. 3. Phylogenetic tree showing relationships between root-nodule bacteria (AjuPt6, SafPt6, SafPt12, AviSp7, and ArrPt12) and reference strains of rhizobia. The tree was drawn to scale, with branch lengths in the same units as those of the evolutionary distances used to infer the phylogenetic tree.

separately from the other Biserrula isolates, and distinguished between R. leguminosarum subspecies phaseoli (EF141340), $R$. leguminosarum bv. trifolii (U31074), and R. leguminosarum bv. viciae (U89831). Azorhizobium caulinodans (X67221), Bradyrhizobium japonicum (AF363150), and Bradyrhizobium lupini (X87273), more phylogenetically related, played an outgroup role.

\section{DISCUSSION}

Molecular fingerprints produced were very complex for all bacterial isolates, showing as documented, good discrimination power of rep-PCR amplification (De Bruijn, 1992; De Bruijn et al., 1996; Wang et al., 2008). The BOX + ERIC combined dendrogram distributed bacterial isolates along a Jaccard coefficient ranging from $44 \%$ to $100 \%$ similarity, denoting therefore considerable genetic diversity among root-nodule bacteria and an association with $B$. pelecinus. The dendrogram analysis was based on the level of similarity of Biserrula isolates to the reference microsymbiont Mesorhizobium species (Nandasena et al., 2001). The most related root-nodule bacteria to Mesorhizobium species were primarily located in Group A, whereas Group B gradually enclosed the most dissimilar bacterial strains. To confirm the cluster distribution, the cophenetic correlation coefficient was calculated and found to be high (between $80 \%$ and $90 \%$ ), therefore, suggesting a good fit of the original data (Romesburg, 1984). The topology of the dendrogram showed no relationship between the disposition of Biserrula isolates and geographic sites. Similar studies with mesorhizobia isolated from pulse crop Cicer arietinum L. (chickpea) indicated that the high genetic diversity found among chickpea isolates did not correlate with their geographic origin within Portugal (Laranjo et al., 2004 and 2008). Jarabo-Lorenzo et al. (2003) obtained the same result working with bradyrhizobial populations of Lupinus species and Ornithopus species that originated in different countries and as well as continents.

The 16S rRNA gene sequencing revealed that the randomly chosen root-nodule bacteria from Group A, AjuPt6, SafPt12, SafPt6, and AviSp7 from group B were recognized, at strain level, as being similar to M. ciceri bv. biserrulae. This result is supported by Nandasena et al. (2007), who identified the specific microsymbiont of $B$. pelecinus belonging to Mesorhizobium genus and who more recently proposed $M$. ciceri bv. biserrulae because of significant divergences with strains of $M$. ciceri (Nandasena et al., 2007). The most interesting result obtained by BLASTN sequence comparison lays on isolate ArrPt12 (Group B), which is the most unrelated strain to Mesorhizobium and which was designated as R. leguminosarum bv. phaseoli. Howieson et al. (1995) classified the symbiotic relationship established between Biserrula and acid-tolerant rhizobia as extremely specific. They demonstrated through cross-inoculation tests that $R$. leguminosarum bv. trifolii, $R$. leguminosarum bv. viciae, Sinorhizobium meliloti, and Bradyrhizobium species were unable to infect Biserrula. Whereas in our study, we have identified R. leguminosarum as one of the strains extracted from a Biserrula nodule.

The phylogenetic tree distribution corroborates the previous results. The isolate AviSp7 was clustered closely with M. ciceri subspecies biserrulae, emphasizing the low percent nucleotide mismatches (approximately $0.792 \%$ ). The AjuPt6 and SafPt6 group clustered with SafPt 2 and gradually branched with AviSp7, explaining the nucleotide mismatches obtained in relation to the reference strain. Sahgal and Johri (2006) suggests that the $5 \%$ nucleotide mismatch used in practice to place individual strains in separate genera has become questionable in 
current rhizobia taxonomy because of lateral gene transfer (LTG) and recombination between rhizobia strains. The fact that the 16S rRNA gene sequencing was based only in a partial fragment of the total gene sequence may also help to justify the percents obtained by AjuPt6 (6.83\%), SafPt (5.05\%), and SafPt6 (4.15\%). The main genera of rhizobia, Mesorhizobium, Sinorhizobium, Bradyrhizobium, and Rhizobium, were disposed in accordance with Kwon et al. (2005), who, using 16S rRNA gene and internally transcribed spacer region sequencing, inferred the phylogenetic relationships between these genera. In agreement with the previous discussion, isolate ArrPt12 clustered with $R$. leguminosarum bv. phaseoli, R. leguminosarum bv. Trifolii, and $R$. leguminusarum bv. viciae in the phylogenetic tree. Although the genetic diversity of Biserrula root-nodule bacteria was substantial, 16S rRNA gene sequencing showed that the most related isolates with Mesorhizobium species in the dendrogram were taxonomically identified as $M$. ciceri bv. biserrulae and that the most distant isolate belonged to other genera of rhizobia. Several studies have suggested LTG of nodulation and nitrogen fixation genes between different species as the most likely hypothesis explaining the promiscuity of rhizobia bacteria (Boucher et al., 2003; Wang et al., 2008). Lu et al. (2009) proved the existence of LTG of symbiotic genes from Mesorhizobium to Bradyrhizobium and among Mesorhizobium species in Caragana species. In addition, LTG has also been reported in species of Mesorhizobium in B. pelecinus (Nandasena et al., 2007). It is in our best interest to infer the ability of ArrPt12 to nodulate Biserrula by analysis of symbiosis and core genes.

The increasing interest in this legume, extensively studied for agricultural uses in southern Australia (Carr et al., 1999; Howieson et al., 1995; Loi et al., 1999; 1997; 2001), is progressively expanding to Europe and South American countries (Barradas et al., 2002; Simões et al., 2004; Ovalle et al., 2004, Tamura et al., 2007). Its good adaptation in the agricultural systems, under Mediterranean climate influence, of the Iberian Peninsula depends greatly on the discovery of native elite mesorhizobia for nitrogen fixation. In the present study, we emphasize, once more, the specificity of the symbiosis rhizobiaBiserrula. From the analysis conducted, 56 different bacterial isolates were already chosen for the selection of native bacteria for inoculant development.

\section{Nucleotide Sequence Accession Numbers}

All sequences have been deposited in GenBank under the accession numbers EU527879, EU527880, EU527881, EU527882, and EU527883.

\section{ACKNOWLEDGMENT}

This work was supported by a doctoral research grant (SFRH/BD/17252/2004) from the Portuguese Foundation for Science and Technology (FCT).

\section{REFERENCES}

Backeljau, T., L. De Bruyn, H. De Wolf, K. Jordaens, S. Van Dongen, T. Winnepenninckx, and B. Winnepenninckx. 1996. Multiple UPGMA and neighbor-joining trees and the performance of some computer packages. Mol. Biol. Evol. 13:309-313.

Barradas, A., G. Pereira, F. Ricardo, M. M. Tavares de Sousa, V. Moreno, and F. González. 2002. Estudo da biodiversidade de espécies leguminosas pratenses em pastos de montado-III-Biserrula pelecinus L., Ornithopus compressus L., Lotus conimbricensis Brot., Scorpirus muricatus L. e Scorpirus vermiculatus L. Melhoramento (Elvas) 38:173-185.
Boucher, Y., C. J. Douady, R. T. Papke, D. A. Walsh, M. E. R. Boudreau, C. L. Nesbo, R. J. Case, and W. F. Doolittle. 2003. Lateral gene transfer and the origins of prokaryotic groups. Annu. Rev. Genet. 37:283-328.

Carr, S. J., A. Loi, J. G. Howieson, and C. Porqueddu. 1999. Attributes of Biserrula pelecinus L. (Biserrula): A new pasture for sustainable farming on acidic sandy soils in Mediterranean environments. Cah. Options Méditerr. 39:87-90.

De Bruijn, F. J. 1992. Use of repetitive (repetitive extragenic palindromic and enterobacterial repetitive intergeneric consensus) sequences and the polymerase chain reaction to fingerprint the genomes of Rhizobium meliloti isolates and other soil bacteria. Appl. Environ. Microbiol. 58: 2180-2187.

De Bruijn, F. J., J. Rademaker, and M. Schneider. 1996. Rep-PCR genomic fingerprint of plant-associated bacteria and computer assisted phylogenetic analysis. In Biology of Plant-Microbe Interaction. Proceedings of 8th International Congress of Molecular Plant-Microbe Interactions. G. Stacey, B. Mullin, and P. Gresshoff (eds.). APS Press, St Paul, MN. 497-502.

Felsenstein, J. 1985. Confidence limits on phylogenies: An approach using the bootstrap. Evolution. 39:783-791.

Howieson, J. G., A. Loi, and S. J. Carr. 1995. Biserrula pelecinus L. A legume pastures species with potential for acid duplex soils which is nodulated by unique root-nodule bacteria. Aust. J. Agric. Res. 46: 997-1009.

Jarabo-Lorenzo, A., R. Pérez-Galdona, J. Donate-Correa, R. Rivas, E. Velázquez, M. Hernández, F. Temprano, E. Martínez-Molina, T. RuizArgueso, and M. León-Barrios. 2003. Genetic diversity of bradyrhizobial populations from diverse geographic origins that nodulate Lupinus spp. and Ornithopus spp. Syst. Appl. Microbiol. 26:611-623.

Jordan, D. C. 1984. Family III: Rhizobiaceae. In Bergey's Manual of Systematic Bacteriology, vol. 1. J. G. Holt and N. R. Krieg (eds.) Williams \& Wilkins Co., Baltimore, MD. pp. 234-256.

Jukes, T. H., and C. R. Cantor. 1969. Evolution of protein molecules. In Mammalian Protein Metabolism. H. N. Munro (ed.). Academic Press, New York, NY.

Kwon, S. W., J. Y. Park, J. S. Kim, J. W. Kang, Y. H. Cho, C. K. Lim, M. A. Parker, and G. B. Lee. 2005. Phylogenetic analysis of the genera Bradyrhizobium, Mesorhizobium and Sinorhizobium on the basis of $16 \mathrm{~S}$ rRNA gene and internally transcribed spacer region sequences. Int. J. Syst. Evol. Microbiol. 55:263-270.

Laranjo, M., J. Machado, J. Peter, W. Young, and S. Oliveira. 2004. High diversity of chickpea Mesorhizobium species isolated in a Portuguese agricultural region. FEMS Microbiol. Ecol. 48:101-107.

Laranjo, M., A. Alexandre, R. Rivas, E. Velázquez, J. P. W. Young, and S. Oliveira. 2008. Chickpea rhizobia symbiosis genes are highly conserved across multiple Mesorhizobium species. FEMS Microbiol. Ecol. 66: 391-400.

Loi, A., J. G. Howieson, and S. J. Carr. 2001. Register of Australian Herbage Cultivars. B. Legumes. 25. Biserrula Biserrula pelecinus L. (biserrula) cv. Casbah. Aust. J. Exp. Agric. 41:841-842.

Loi, A., J. G. Howieson, P. S. Cocks, and S. J. Carr. 1999. Genetic variation in populations of two Mediterranean annual pasture legumes (Biserrula pelecinus L. and Ornithopus compressus L.) and associated rhizobia. Aust. J. Agric. Res. 50:303-313.

Loi, A., P. S. Cocks, J. G. Howieson, and S. J. Carr. 1997. Morphological characterization of Mediterranean populations of Biserrula pelecinus $\mathrm{L}$. Plant Breed. 116:171-176.

Lu, Y. L., W. F. Chen, E. T. Wang, S. H. Guan, X. R. Yan, and W. X. Chen. 2009. Genetic diversity and biogeography of rhizobia associated with Caragana species in three ecological regions of China. Syst. Appl. Microbiol. [doi:10.1016/j.syapm.2008.10.004].

Mantel, N. 1967. The detection of disease clustering and a generalized regression approach. Cancer Res. 27:209-220. 
Marchesi, J. R., T. Sato, A. J. Weightman, T. A. Martin, J. C. Fry, S. J. Hiom, and W. G. Wade. 1998. Design and evaluation of useful bacteriumspecific PCR primers that amplify genes coding for bacterial 16S rRNA. Appl. Environ. Microbiol. 64:795-799.

Nandasena, K. G., G. W. O'Hara, R. P. Tiwari, A. Willems, and J. G. Howieson. 2007. Mesorhizobium ciceri biovar biserrulae, a novel biovar nodulating the pasture legume Biserrula pelecinus L. Int. J. Syst. Evol. Microbiol. 57:1041-1045.

Nandasena, K. G., G. W. O’Hara, R. P. Tiwari, R. J. Yates, B. D Kishinevsky, and J. G. Howieson. 2004. Symbiotic relationships and root nodule ultrastructure of the pasture legume Biserrula pelecinus L.-A new legume in agriculture. Soil Biol. Biochem. 36:1309-1317.

Nandasena, K. G., G. W. O'Hara, R. P. Tiwari, R. J. Yates, and J. G. Howieson. 2001. Phylogenetic relationships of three bacterial strains isolated from pasture legume Biserrula pelecinus L. Int. J. Syst. Evol. Microbiol. 51:1983-1986.

Ovalle, M. C., S. Arredondo, A. del Pozo, J. Avendaño, and E. Fernández. 2004. Attributes and behavioral background of Biserrula pelecinus L. A new annual forage legume for Mediterranean Chile. Agric. Tec. 64:74-81.

Romesburg, H. C. 1984. Cluster Analysis for Researchers. Lifetime Learning Publications, Belmont, CA. pp. 24, 143.
Rohlf, F. J. 1990. NTSYS-pc Numerical Taxonomy and Multivariate System, version 2.01. Exeter software. Setauket, New York, NY.

Sahgal, M., and D. N. Johri. 2006. Taxonomy of rhizobia: Current status. Curr. Sci. 90(1):43-48.

Saitou, N., and M. Nei. 1987. The neighbor-joining method: A new method for reconstructing phylogenetic trees. Mol. Biol. Evol. 4:406-425.

Sambrook, J., and D. Russel. 2001. Molecular cloning: A laboratory manual, 3rd Ed, 3rd vol. Cold Spring Harbor Laboratory Press, Cold Spring Harbor, NY. p. A1.16.

Simões, N., M. M. Tavares-de-Sousa, and A. R. Costa. 2004. Estudo Comparativo de Leguminosas Anuais Pratenses-Biserrula pelecinus L. e Ornithopus compressus L. Pastagens Forrag. 24:97-108.

Tamura, K., J. Dudley, M. Nei, S. Kumar. 2007. MEGA4: Molecular Evolutionary Genetics Analysis (MEGA) software version 4.0. Mol. Biol. Evol. 24:1596-1599.

Vincent, J. M. 1970. A Manual for the Practical Study of Root-Nodule Bacteria. IBP Handbook No. 15. Blackwell Scientific Publications, Oxford, UK.

Wang, H., C. X. Man, E. T. Wang, and W. X. Chen. 2008. Diversity of rhizobia and interactions among the host legumes and rhizobial genotypes in an agricultural-forestry ecosystem. Plant Soil. 314:169-182 [DOI 10.1007/s11104-008-9716]. 